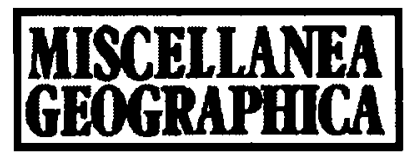

WARSZAWA 2000 Vol. 9

Michał K. Kowalewski

\title{
THE WINTER ROUTES OF CYCLONES OVER EUROPE ${ }^{*}$
}

In the latitudes, in which Europe is situated, one of the primary weather conditioning factors is the variability of atmospheric pressure configurations. The field of pressure changes over time, and its most characteristic forms are highs and lows of air pressure. These pressure settings are closely linked with the circulation configurations of cyclones and anticyclones. The pressure and circulation configurations move with respect to the earth's surface, bringing thereby about various weather changes.

Pressure lows, as compared to the high pressure forms, are very dynamic configurations. They are accompanied by fronts, characteristic cloud formations, and sequences of weather changes, which have a disadvantageous influence on both human organism and some sectors of economy.

The primary purpose of the study here reported was to determine the routes along which the low pressure configurations move over Europe and the north-eastern part of the Atlantic Ocean during winter months.

The weather during the analysed winters of the five-year period 1993/4$1997 / 8$ was atypical. In Poland, these winters were warm and snow-less. In view of this, the results obtained, describing the atypical winters, present an interest as a comparative material.

The problem of determination of routes, along which the cyclones move, is one of the oldest questions taken up by meteorology and climatology. Determination of these routes was first of all very important for sea navigation. No wonder, therefore, that already in the 1870s the German Maritime Observatory disposed of the maps of routes along which pressure configurations move (Wiktorowski, 1995).

One of the best known historical studies concerning the routes of cyclones is the work by W. Van Bebber, concerning the period 1876-1880 (Wiktorowski, 1995). The same issue was taken up yet many times over with respect to various periods and areas (Gerasimov, 1964; Roth, 1990; Rumney, 1968).

* This report is a summary of the M.A. dissertation written under the guidance of Krzysztof Olszewski. 
An important part of reports, which concern cyclones over Europe, deals only with the frequency of their appearance. Such studies were conducted by, in particular, L.Buchert, both on the local scale (1994) and on the continental one (1990). Of the more recent studies one should mention the research reported by J. Wiktorowski (1995), who determined 12 routes of the European cyclones, using for this purpose the material from the years 1970 1979.

The present study was conducted on the basis of maps published in the Daily Meteorological Bulletin of the Institute of Meteorology and Water Management, presenting the distribution of atmospheric pressure at the sea level at 00:00 GMT. The meteorological winter months were analysed, starting with December 1993 and ending with February 1998. It was assumed that all those cyclones would be accounted for which are marked on at least one map with at least two closed isobars. On the basis of these maps the centres of the low pressure configurations were determined for each day of the period analysed. After the identification of the configurations on consecutive maps their centres were connected with the straight lines. In this manner the routes of all cyclones, which moved over Europe, were obtained.

The study reported here analysed the frequency of appearance of cyclones, the areas from which the routes of the European cyclones start and where they end, as well as the routes along which they move during the whole period of their presence within the territory considered.

The present report was elaborated on the basis of the material covering almost whole of Europe, as well as a part of the Atlantic Ocean, including the entire basin located between Iceland, the coasts of the Scandinavian Peninsula, and the British Isles.

\section{FREQUENCY OF APPEARANCE OF CYCLONES}

During the months analysed altogether 249 cyclones appeared over Europe and the north-eastern Atlantic (Table 1). Of these, 56 existed over the area considered for a period shorter than 24 hours - for the most part these were the cyclones, which moved over the Atlantic Ocean close to the Iceland's coasts. The largest group was constituted by the one-day cyclones, of which 98 were observed (Table 1 ). There were twice less of the two-day cyclones. Thus, altogether 203 cyclones observed - i.e. $82 \%$ of the total were present within the area considered for a time shorter than three days. When analysing the numbers of cyclones, which appeared during individual months, one notices a decidedly higher number of cyclones appearing in February, although these are primarily the cyclones, whose duration is shorter than two days. The biggest number of cyclones with duration of two or more days was observed in January, when altogether the lowest number of low atmospheric pressure configurations was observed.

During $65 \%$ of winter days at least one low air pressure configuration 
Number of cyclones with different duration

\begin{tabular}{|c|r|r|r|r|r|}
\hline \multirow{2}{*}{ Duration in days } & \multirow{2}{*}{ December } & \multirow{2}{*}{ January } & \multirow{2}{*}{ February } & \multicolumn{2}{|c|}{ Winter } \\
\cline { 5 - 6 } & & & & number & $\%$ \\
\hline Less than 1 & 19 & 16 & 21 & 56 & 23 \\
1 & 36 & 21 & 41 & 98 & 39 \\
2 & 11 & 21 & 17 & 49 & 20 \\
3 & 7 & 14 & 12 & 33 & 13 \\
4 & 5 & 5 & 1 & 222 & 4 \\
5 & 1 & 1 & & 2 & 1 \\
\hline Total & 79 & 78 & 92 & 249 & 100 \\
\hline
\end{tabular}

existed over Europe and the north-eastern Atlantic. Situations in which one, two or three cyclones exist within the area considered, take place during more than half of winter days. The situations with four or more of low air pressure centres appear much less frequently - in only $13 \%$ of days.

In terms of the consecutive winter months the frequency of appearance of days with cyclones increases from 60\% in December, through 62\% in January, to $72 \%$ in February. During the five winters analysed there occurred 68 situations when for at least 24 hours no low air pressure centre existed over the area considered.

The spatial distribution of the frequency of appearance of days with cyclones during winter is presented in Fig. 1a. Three areas of a distinctly higher frequency are visible in Europe, namely over the North Sea, over the Baltic Sea, and over the Mediterranean and Adriatic Seas. The first two of these areas are linked over Denmark by a zone, which features an only slightly smaller frequency of this phenomenon. The third, southern area is separated from the previous two by a region where the frequency of occurrence of cyclones is low, this region stretching from the Iberian Peninsula through Central Europe to the south-eastern part of the continent. Attention should also be paid to the Scandinavian Peninsula, which is characterised by a distinctly lower frequency of appearance of cyclones in comparison with the surrounding seas.

In the analysis of the phenomenon studied for the particular winter months one notices first of all the bigger maximum frequency. This is connected with the changes of the cyclone activity in the particular parts of the analysed area, although its general distribution is similar to the winter distribution. Thus, in December (Fig. 1b) a very high cyclone activity can be observed over the North Sea (8\%) and over the Atlantic ocean, in the area located to the east of the Färöe Islands (6\%). High activity is also observed over the Apennine Peninsula (4\%) and over the north-eastern part of the Valachian Lowland (4\%).

In January (Fig. 1c), the frequency of appearance of the cyclones over the whole area considered decreases. This decline is most visible over the North Sea (4\%). The Atlantic region of high activity moves to the west. The zone 

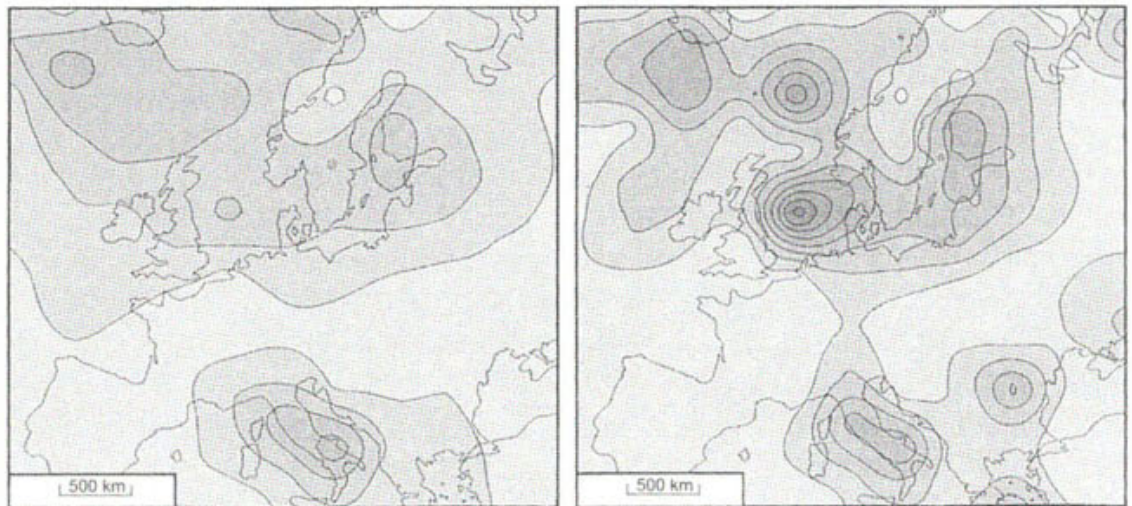

a) winter

b) December
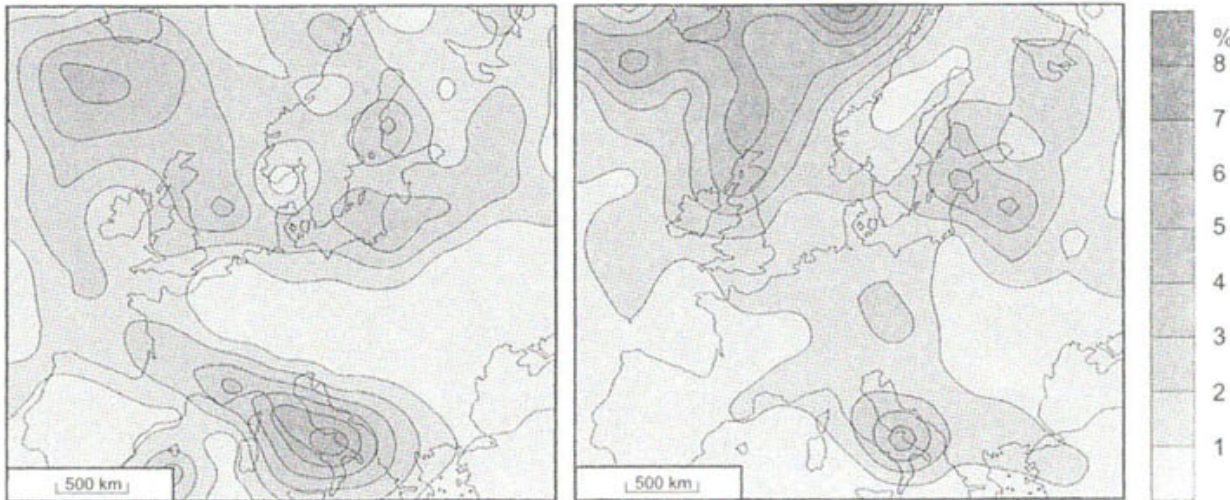

c) January

d) February

Fig. 1. Frequency of appearance of cyclones: $a-$ winter, b - December, c - January, d-February.

linking the Apennine region with the northern part of the Atlantic Ocean changes its course and leads over the Bay of Biscay through the Atlantic ocean, to the west of the British Isles, in the direction of Iceland. The area of high frequency of appearance of the cyclones over the Baltic Sea shrinks as well.

In February (Fig. 1d), the situation over the southern Europe reminds of the situation from December. The highest frequency in this part of the continent is observed over the Apennine Peninsula and is equal 4\%. The zone linking the southern area with the Atlantic Ocean leads again in the direction of the North Sea, where cyclones appear with frequency of 2-3\%. This value increases in the north-eastern direction and reaches over the Atlantic Ocean 5\%. The Baltic zone of high frequency of cyclones moves to the southeast and encompasses the central part of the Baltic Sea together with the Lithuanian Lowland.

The decidedly more complex spatial distribution of the phenomenon when 
appraised in particular months than for the whole of winter is the effect of the smaller number of days, from which the data come, so that the single atypical situations can exert a stronger influence on the average image of the phenomenon.

\section{CYCLONE ROUTES}

During the winter months of the period here considered 193 low air pressure centres were observed over Europe and the north-eastern part of the Atlantic Ocean, such that their duration was longer than 24 hours, i.e. their presence was noted on at least two maps from the consecutive days. Their numbers in December and January differed only insignificantly, while there were clearly more of them in February (Table 1). Since February has three days less than both January and December, this difference becomes even more pronounced. It is first of all the result of the large number (40\%) of the one- and two-day cyclones, which account together for more than $75 \%$ of all the observed cyclones.

\section{REGIONS OF THE STARTING POINTS OF ROUTES}

Determination of the routes, over which European cyclones move, was preceded by the attempt of identification of the areas where they start. For this purpose a map was elaborated presenting the locations of the initial points of the routes observed. It must be noted here that there are in fact two kinds of such starting points: locations, where the cyclone actually appeared, and locations, where it was marked on the first day after it had moved into the area analysed. Then, distances were calculated between these starting points and it was assumed that the starting points distanced by less than $250 \mathrm{~km}$ belong to one group. An important reason for accepting this particular threshold distance was a satisfactory conformity of the regions obtained with the physico-geographical conditions. Finally, the boundaries of the regions were slightly modified by tracing them in accordance with the surface relief.

Thus, nine definite regions were determined, in which the observed routes start (Fig. 2a):

North-eastern Atlantic (1), Norwegian Sea (2), Irish Sea (3 - treated separately from the Atlantic region in view of a different bedding), Bay of Biscay (4), Gulf of Bothnia (5), encompasses the very Gulf of Bothnia, the lowlands around it, and the Finnish Lakeland, to the west there are the Scandinavian Mountains, due to which the region offers advantageous conditions for the orographic cyclogensis), Lithuanian Lakeland (6), German Plain (7), Po river plain (8), and southern Apennines (9). The data concerning the activity in the particular regions are shown in Table 2 . This activity is quite 

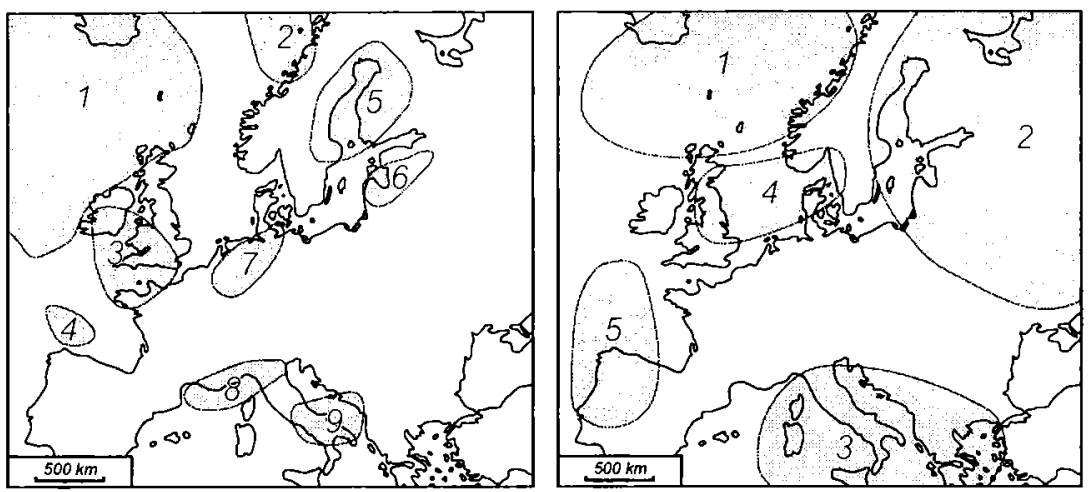

Fig. 2. Regions of the starting (a) and ending (b) points of European cyclone routes.

even across the months. The biggest differentiation of the number of emerging cyclones was observed in the region of the Bay of Biscay, but, on the other hand, this is the region with the lowest activity during the whole of winter. In the region of the north-eastern Atlantic an increased activity is noted in February. Since in February the ratio of the number of low pressure centres emerging in the Atlantic region to the number of all such configurations is higher than in the remaining months, it can be expected that a higher activity in this region will bring about a general increase of the number of cyclones in February.

Table 2.

Number of routes starting in definite regions during winter months and the whole of winter

\begin{tabular}{|l|r|r|r|r|r|r|r|r|}
\hline \multirow{2}{*}{ Region } & \multicolumn{2}{|c|}{ December } & \multicolumn{2}{c|}{ January } & \multicolumn{2}{c|}{ February } & \multicolumn{2}{c|}{ Winter } \\
\cline { 2 - 9 } & number & \multicolumn{1}{c|}{$\%$} & number & \multicolumn{1}{c|}{$\%$} & number & \multicolumn{1}{c|}{ number } & \multicolumn{1}{c|}{$\%$} \\
\hline NE Atlantic & 30 & 50 & 33 & 53 & 41 & 58 & 104 & 54 \\
Norwegian Sea & 3 & 5 & 1 & 2 & 3 & 4 & 7 & 4 \\
Irish Sea & 4 & 7 & 2 & 3 & 6 & 8 & 12 & 6 \\
Bay of Biscay & 1 & 2 & 4 & 6 & 0 & 0 & 5 & 3 \\
Gulf of Bothnia & 5 & 8 & 2 & 3 & 7 & 10 & 14 & 7 \\
Lithuanian & & & & & & & & \\
Lakeland & 1 & 2 & 1 & 2 & 3 & 4 & 5 & 3 \\
German Plain & 2 & 3 & 3 & 5 & 1 & 1 & 6 & 3 \\
Po river plain & 2 & 3 & 4 & 6 & 4 & 6 & 10 & 5 \\
Apennines & 3 & 5 & 3 & 5 & 2 & 3 & 8 & 4 \\
Other areas & 9 & 15 & 9 & 13 & 4 & 6 & 22 & 11 \\
\hline Total & 60 & 100 & 62 & 100 & 71 & 100 & 193 & 100 \\
\hline
\end{tabular}

REGIONS OF THE ENDPOINTS OF ROUTES

Using a method analogous to the one applied for the starting points in which the European cyclone routes start, the regions were determined where 
they end. Similarly as in the case of the starting points, their ends are of a double nature: either the low air pressure centre disappears by getting filled, or it leaves the area considered. The following regions were established (Fig. 2b): Atlantic (1), Eastern-European (2), Southern-European (3), North Sea (4), and Bay of Biscay (5).

Information on the number of routes ending in the regions mentioned for particular months is given in Table 3 .

Table 3 .

Numbers of routes ending in definite regions in winter months and in the whole of winter

\begin{tabular}{|l|r|r|r|r|r|r|r|r|}
\hline \multirow{2}{*}{ Region } & \multicolumn{2}{|c|}{ December } & \multicolumn{2}{c|}{ January } & \multicolumn{2}{c|}{ February } & \multicolumn{2}{c|}{ Winter } \\
\cline { 2 - 9 } & number & \multicolumn{1}{c|}{$\%$} & number & \multicolumn{1}{c|}{$\%$} & number & $\%$ & number & \multicolumn{1}{c|}{$\%$} \\
\hline Atlantic & 15 & 25 & 15 & 24 & 22 & 31 & 52 & 27 \\
Eastern European & 27 & 45 & 24 & 39 & 27 & 38 & 78 & 40 \\
Southern European & 8 & 13 & 14 & 23 & 10 & 14 & 32 & 17 \\
North Sea & 4 & 7 & 2 & 3 & 4 & 6 & 10 & 5 \\
Bay of Biscay & 1 & 2 & 4 & 6 & 2 & 3 & 7 & 4 \\
Other areas & 5 & 8 & 3 & 5 & 6 & 8 & 14 & 7 \\
\hline Total & 60 & 100 & 62 & 100 & 71 & 100 & 193 & 100 \\
\hline
\end{tabular}

Similarly as in the case of the starting point regions, here also no important changes of the number of cyclones for particular months are observed. The largest differences were observed in the region of Bay of Biscay, while the most even activity in particular months was noted in the Eastern European region.

\section{CYCLONE CORRIDORS}

The routes of the low pressure configurations were grouped according to the regions, in which they start and end. Then, their course was analysed, and, based upon a subjective assessment of their similarity, the corridors were determined, along which these routes go, accounting for those corridors only which group at least five similar routes. An attempt was made to trace the axis of the corridor as the centre line between the extreme routes classified in the same group. The corridors were numbered according to the quantity of cyclones moving within them (Fig. 3).

The largest group was constituted by the cyclones whose routes started and ended over the Atlantic Ocean. There were 47 such cases (14 in December, 12 in January, and 21 in February), which is equivalent to $25 \%$ of all the cyclones observed. The thus high activity related to this region, appearing as a pair, is exactly the result of its overlapping or incidence. Owing to this, the corridor includes both the one-day cyclones, which appeared and disappeared over the fragment considered of the Atlantic Ocean, and those which moved from the western and central parts of the ocean, close to the coasts of 


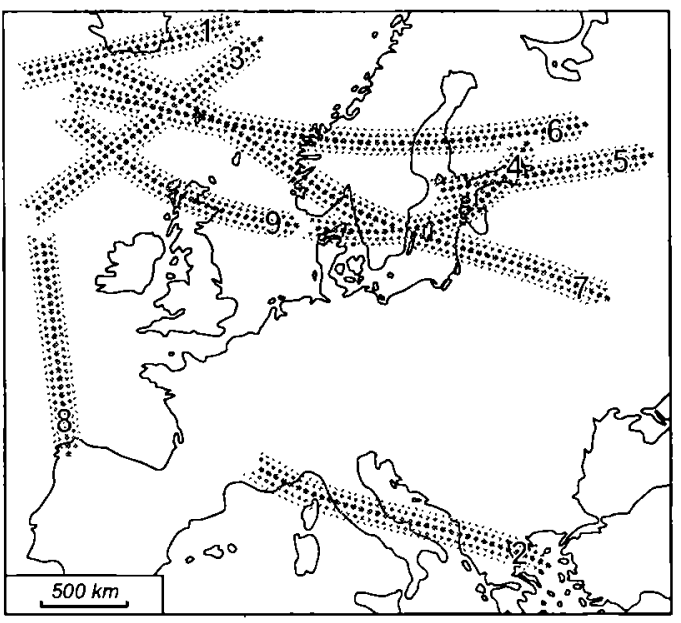

Fig. 3. The winter cyclone corridors.

Iceland, in order then to leave the area analysed. This group contains 30 single-day routes (one-third of such routes). The average time of presence over the area considered of the cyclones belonging to this group is 1.5 days, and they move within two corridors, denoted with numbers I and III, as well as within the first part of the corridor number VI.

The second group, in terms of the number of cyclones, is the one with the routes starting over the Atlantic Ocean, and terminate in the Eastern

European region. This group contains 35 cyclones (11 having occurred in December, 14 in January, and 10 in February), accounting for $18 \%$ of all the cases observed. These cyclones usually omit the Scandinavian Mountains. Over Eastern Europe the cyclones belonging to this group as a rule change their direction, turning to the left, and disappear, although 10 of them also left the area of study in the eastern direction. The group encompasses 18 cyclones whose duration extended over three or more days, that is $-38 \%$ of all such cases. The average time of presence over the area considered of the low air pressure centres belonging to this group was 2.7 days. The cyclones here classified moved along three corridors, denoted with numbers IV, VI and VII.

The subsequent group is constituted by the cyclones beginning in the area of the Gulf of Bothnia or the Lithuanian Lakeland, and ending in the Eastern European region. In view of the mutual position of these regions, the relation of their magnitude, and the dominating direction of the cyclone movement to the east, the routes of all the 14 cyclones starting over the Baltic Sea, in the area of the Gulf of Bothnia, and of the five cyclones starting in the region of the Lithuanian Lakeland, must have ended in Eastern Europe. The majority of cyclones belonging to this group exist for just one day, the average time of their presence over Europe is 1.2 days, and they move in the corridor denoted $\mathrm{V}$.

The low atmospheric pressure areas, which start out from the river Po plain or in the Apennines, and ending in the South- European region constitute the fourth group, containing altogether 14 cases. These cyclones stayed within the area considered on the average over 1.5 days, to then in the majority of cases leave this area in the south-eastern direction. The corridor, which contains their routes was denoted as II.

The group composed of eight cases is constituted by those low pressure 
configurations which appeared in the Atlantic region, and some two days later filled out in the region of the North Sea. The routes of these cyclones were contained within a similar corridor as the previously mentioned group of 18 cyclones moving from the region of the Atlantic Ocean, over Scania, toward the Eastern European region. Five cyclones from this group moved along the first part of the corridor IV, denoted as corridor IX.

The last group is constituted by the low pressure centres moving from the Atlantic region to the Bay of Biscay. It contains six cyclones. The average time for covering this distance was 1.2 days. The respective corridor was denoted VIII.

The number of cyclones, which moved during the five winters considered between the remaining pairs of regions where cyclones appeared and disappeared, did not exceed five. Altogether $45 \%$ of cyclones moved within the corridors determined above. The other ones moved in such a manner that it was not possible to determine the subsequent corridors.

The level of activity within the corridors commented upon changes in particular months. As can be seen from Table 4, the highest repetitiveness of route types was observed in January, when exactly half of all the cyclones moved along the corridors described. This is most probably the result of the change of cyclone routes in the area of the Mediterranean Sea, as indicated by the percentage share of cyclones moving along the corridor II, which is the highest in this month. Attention should also be paid to the fact that all the cyclones emerging in this region moved along the corridor II in January, while during the remaining winter months cyclones whose routes belonged to this corridor constituted approximately $60 \%$ of those appearing over the

Table 4

Activity within the particular corridors during particular winter months and the whole winter The ratio of the number of cyclones within the corridor to the total number of cyclones in the time interval considered (in \%)

\begin{tabular}{|c|c|c|c|c|}
\hline Corridor & December & January & February & Winter \\
\hline I & 7 & 6 & 11 & 8 \\
II & 5 & 11 & 6 & 7 \\
III & 5 & 5 & 8 & 6 \\
IV & 7 & 5 & 3 & 5 \\
V & 0 & 5 & 8 & 5 \\
VI & 5 & 5 & 3 & 4 \\
VII & 2 & 6 & 3 & 4 \\
VIII & 2 & 5 & 3 & 3 \\
IX & 5 & 2 & 1 & 3 \\
Outside & 63 & 50 & 54 & 55 \\
of corridors & & &
\end{tabular}

Mediterranean Sea. At the same time, there was a higher share of cyclones moving outside of the corridors determined. In February, the most active was the corridor I, along which $11 \%$ of all cyclones moved. In the same 
month a higher activity over the corridor III was observed. Simultaneously, a decrease in activity within the corridors IV, VI and VII was observed. It can be stated that the number of cyclones moving along the coasts of the Scandinavian Peninsula increases, while the number of those moving over the Baltic Sea decreases.

The analysis conducted with respect to the motion of cyclones allows for formulation of the following conclusions:

The repetitiveness of the winter routes of cyclones over Europe is low. Only $45 \%$ of cyclones appearing over the area analysed moved along the nine route corridors determined. The majority (54\%) of cyclones moving during winter over Europe emerged over Atlantic Ocean. They would appear within the area considered for the first time to the south of the coast of Iceland.

The cyclone activity attains its maximum during winter in February, when $37 \%$ of all the winter cyclones move over the area analysed. This is connected with the increased activity of the Icelandic Low, and of the cyclone corridor leading across the Atlantic Ocean and the Norwegian Sea in the north-eastern direction, over the Barents Sea.

\section{REFERENCES}

Buchert L., 1990, Częstość występowania ośrodków cyklonalnych nad Europą w pięcioleciu 1981-1985 [Frequency of appearance of the cyclones over Europe in the five year period 1981-1985], Badania Fizjograficzne nad Polska Zachodnia, vol. 41, Series A.

Buchert L., 1994, Występowanie mas powietrza, frontów atmosferycznych, układów barycznych nad Poznaniem w latach 1965-1980 [Appearance of air masses, atmospheric fronts, and pressure systems over Poznan in the years 1965-1980], Badania Fizjograficzne nad Polska Zachodnia, vol. 45, Series A.

Gerasimov I.P. (ed.), 1964, Fiziko-geograficheskii Atlas Mira [Physico-geographical World Atlas], AN SSSR, Moskva.

R o th G.D., 1990, Wetterkünde für alle, BLV, München.

Rumney G.R., 1968, Climatology and the World's Climates, The Macmillan Company, New York.

Wik tor ow ski J., 1995, Ruch układów barycznych w Europie i północnej części Oceanu Atlantyckiego [The dynamics of atmospheric pressure systems in Europe and the northern part of the Atlantic Oceanl, Biuletyn WAT, No. 9. 